\title{
Optimization Process Parameters of Equal Angular Channel Pressing According to the Measurement Results of Microstructural Homogeneity
}

\author{
Asli Günay Bulutsuz *iอ, Mehmet Emin Yurcia, Numan Durakbașa ${ }^{b}$ \\ ${ }^{a}$ Makine Mühendisliği Bölümü, Makine Fakultesi, Yildiz Teknik Universitesi, 34349, Istanbul, Türkiye \\ ${ }^{b}$ Technische Universität Wien, Getreidemarkt, 9, BA09/3113, A-1060, Wien, Österreich
}

Received: April 13, 2018; Revised: July 26, 2018; Accepted: August 06, 2018

\begin{abstract}
The aim of the present work is to discuss process parameters effect on microstructure evolution and formation mechanism of ultrafine grains. As plastic deformation technique Equal Channel Angular Pressing (ECAP) method used pure Ti G4 rods processed in order to obtain fine grained micro structure. Equal Chanel Angular Pressing technique was conducted at different processing route, process temperature, pressing velocity with an orthogonal design to critically evaluate the significance of these process parameters with their different levels. The microstructure was observed with optical and electron back scattering diffraction (EBSD) microscope. The mechanical properties were tested with tensile, hardness tests and phase is controlled with XRD analysis.
\end{abstract}

Keywords: Experimental Design, Optimization, Measurement, ECAP, Titanium.

\section{Introduction}

The influence of severe plastic deformation parameters on ultrafine grained (UFG) material properties has been investigated by various studies; ${ }^{1}$ studied Surrogate-based Pareto analysis for Constrained groove pressing of steel plates, ${ }^{2}$ used Taguchi analysis for repetitive corrugation and straightening (RCS) of Al plates, ${ }^{3}$ used Response Surface Methodology in optimizing the process parameters of Twist Extrusion process of aluminium. This study focused on investigation effects of extrusion mold characteristics and processing route on specimen mechanical homogeneity by means of experimental design. In order to obtain this a comprehensive experimental design was built up to obtain process parameters effect on UFG materials such as process temperature, route and pressing velocity.

ECAP technique introduces material high dislocations to the sample via simple shear at the intersection of the tool channel. Titanium ECAP is also quite different from other materials because of titanium has deformation twinning besides slip of grains ${ }^{4}$. ECAP is a versatile technique that enable manufacturing UFG material with prior mechanical properties $^{5}$. As it is known, during the ECAP the material geometry is not changing which enable repetitive pressing of same specimen with different routes ${ }^{6}$. Different pressing direction routes invoke different deformation planes ${ }^{7,8}$. Based on literature during the first pressing of titanium $\{101 \mathrm{~T}\}$ twinning plane is active afterwards, prismatic, basal and pyramidal slip systems activate. After first pressing, the activation energy for twin nucleation increases thus secondary slip system activates. A homogeneous ultrafine grained microstructure is obtained by activating such

"e-mail: asligunaya@gmail.com different planes. For application of route A the specimen is located to the channel in the same direction for every pressing which means route $\mathrm{A}$ has no rotations. Specimen is rotated with $+90^{\circ}$ for application of route $B_{C}$. For route $\mathrm{C}$, the specimen is rotated with $+180^{\circ} 7,9$. As highlighted in 7 Route $\mathrm{A}$ and $\mathrm{C}$ exhibit sharing in the $\mathrm{X}$ and $\mathrm{Y}$ planes but there is not sharing in the $\mathrm{Z}$ plane. Alternatively, route $\mathrm{B}_{\mathrm{C}}$ has sharing plane in the $\mathrm{Z}$ direction ${ }^{7}$. The shearing planes of Route $\mathrm{C}$ and $\mathrm{B}_{\mathrm{c}}$ can be seen in Figure 1. The shearing planes of Route $\mathrm{C}$ and $\mathrm{Bc}$ are depicted Figure 1. For both $\mathrm{C}$ and $\mathrm{B}_{\mathrm{C}}$ route the specimen is turned at different angles and places to the channel for the second passes. As depicted in the Fig 1. Deformation section invokes -XY axis slip planes. Before second pass for route $\mathrm{C}$ the specimen turned $+180^{\circ}$ that invoked XY planes. For route $\mathrm{BC}$ specimen turned +90 - degrees, due to half turning additional slip direction that belongs to $\mathrm{Z}$ axis are come across with deformation plane of the tool. After fourth pass all $\pm \mathrm{XY}, \pm \mathrm{ZY}$ axes are being deformed due to $90^{\circ}$ turning between each passes. So far, there are plenty of studies about ECAP routes of titanium. They concluded that route $\mathrm{B}_{\mathrm{C}}$ is more effective than the other routes for generating a homogenous; ultrafine grained microstructure with high angle grain boundaries ${ }^{10,11}$. Route $\mathrm{C}$ found to be generating the most intense plastic straining because of repetitive deformation with same plane ${ }^{12,13}$. In this experimental study three different processing routes (A, $\left.\mathrm{B}_{\mathrm{c}}, \mathrm{C}\right)$ were selected to understand shearing behaviour effect to the microstructure homogeneity beyond other processing parameter such as temperature, pressing velocity.

Process temperature is another important parameter considered in this research. Process temperature directly effects productivity of material. Lower process temperatures decreases manufacturing cost and more basic manufacturing infrastructure but besides this increasing process temperature 


\section{Route C}

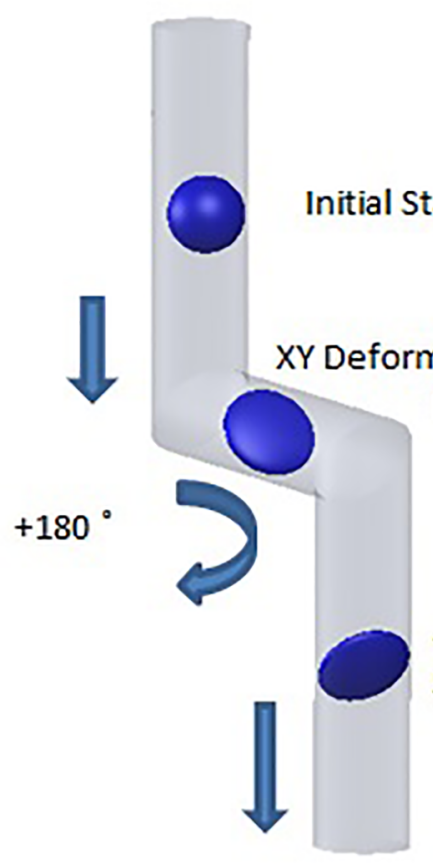

Route $B_{\varepsilon}$

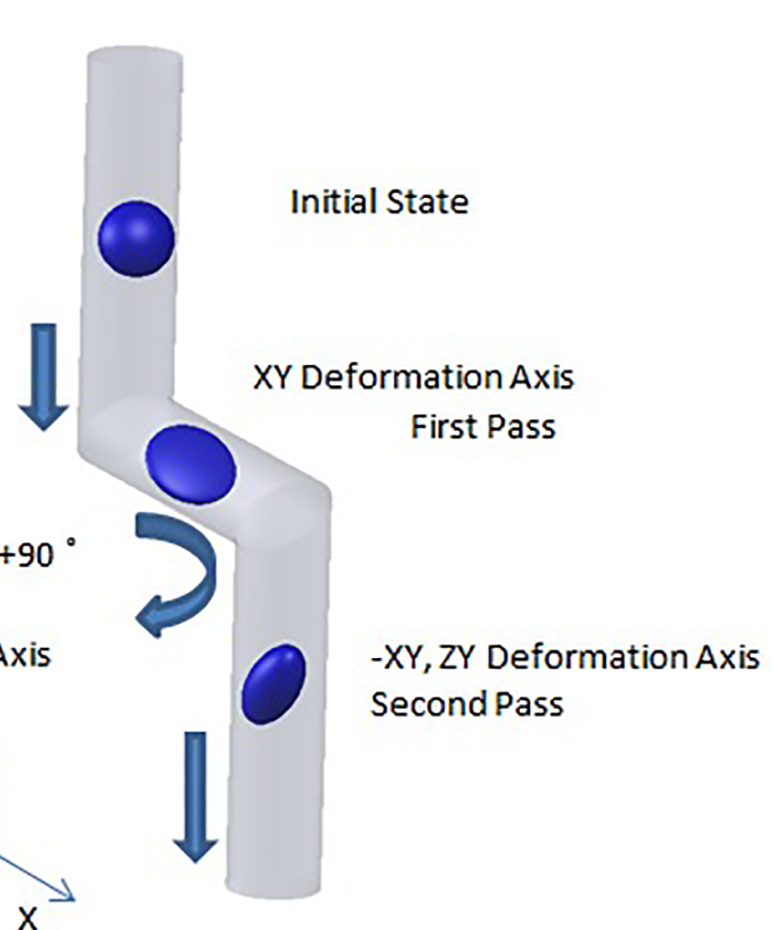

Figure 1. Deformation directions due to ECAP route

decreases tool wear ${ }^{14}$. In addition processing of $\mathrm{CP}$ Ti by plastic deformation is not an easy method because of its poor plastic deformation capability, limited ductility. CP Ti has hexagonal closed packet structure with poor slip system for deformation ${ }^{15}$. The tool wear rates are high during Ti extrusion or machining processes. Different process temperatures may be used to activate different dislocation planes that affect mechanical properties and homogeneity. For example at ambient temperatures there are three different twinning planes $\{1012\},\{112 \mathrm{~T}\}\{1122\}$, for $350{ }^{\circ} \mathrm{C}\{101 \mathrm{~T}\}$ twining plane is active ${ }^{10,16}$. Thus the amount of the twinning in the structure of the material is changeable with deformation temperature. The formation of twins in the microstructure is important for mechanical properties such as ductility ${ }^{17,18}$. In studies generally higher processing temperatures are selected for ECAP of pure Ti to activate additional slip systems and dynamic recrystallization in order to obtain lower deformation strength with a fine micro structure ${ }^{19,20}$. There are also successful studies used lower processing temperatures $\left(275^{\circ} \mathrm{C}\right)$ for pure Titanium ${ }^{21,22}$. High pressing temperature can result with grain growth in the microstructure of material. Even so, lower process temperatures of the hexagonal closed packed titanium result with low ductility and high hardness. In this experimental study three levels of process temperature were selected to understand their effect on grain growth and deformation mechanism. At room temperature ECAP failed with segmentations on specimen for pressing speed $5-0.1 \mathrm{~mm} / \mathrm{s}$. Thus the lowest temperature selected as $150{ }^{\circ} \mathrm{C}$.

Pressing velocity effects micro structure formation by dominating plastic recovery time during deformation, flow stress and internal heating, which is crucial especially for high speed pressing ${ }^{23,24}$. Slower ram speed enables plastic recovery that results with observation extrinsic grain boundary dislocations by the equilibrated grain boundaries. Thus, as $^{8}$ highlighted slow ram speed provides more equilibrated grain boundaries in the structure. Higher pressing speeds cause high flow stress and results with non-equilibrated grain boundaries. Moreover, pressing speed has a significant effect on internal heat increase of the $\operatorname{specimen}^{25,26}$. The heat increase is more significant for higher speeds as can be seen in ${ }^{25,26}$, which can be attributed to the friction rates of materials. In literature there are analytical studies ${ }^{27,28}$ addition to experimental studies to highlight ram speed effect on microstructure of material.

The effect of grain size and pressing speed on the deformation mode of commercially pure Ti during equal channel angular pressing (ECAP), were discussed in the article. The ECAP was carried out on the billets at 150$450{ }^{\circ} \mathrm{C}$ with constant pressing speeds of 0.1 or $5 \mathrm{~mm} / \mathrm{s}$. The ANOVA and Taguchi analysis is calculated based on hardness standard deviation values of specimen groups. The 
optimal experimental set investigated by means of EBSD, $\mathrm{XRD}$, and tensile test.

\section{Experimental Procedures}

In experiments commercially pure titanium grade 4 (ASTM B 348, ISO 5832/2) with an average grain size of $58 \mu \mathrm{m}$ was used. For ECAP, cylindrical samples with the dimension $\varphi 5 \mathrm{~mm} \times 50 \mathrm{~mm}$ were prepared from a titanium bar. In order to remove any residual stress that might remain inside all of samples were annealed in argon atmosphere for $2 \mathrm{~h}$ at $700{ }^{\circ} \mathrm{C}$ and air cooled.

An ECAP die with channel angles of $\varphi=110^{\circ}$ and corner angle of $\Psi=\sim 0^{\circ}$ was used (Fig. 2). Manufacturing corner angle of $\Psi=\sim 0^{\circ}$ at the intersection is quite difficult for 5 $\mathrm{mm}$ diameter with drilling method. Therefore the electrical discharge wire cutting used for its lower manufacturing tolerance interval. Molybdenum disulphide was used as lubricant (MollyDuval). Lubricant material applied to both specimen and channel walls. During the pressing temperature of the die controlled and was kept stable $\pm 10{ }^{\circ} \mathrm{C}$ with a controller (Fig. 2).

Coarse grained specimen micro structure was observed with Leica optical microscope and for ultrafine grained specimen EBSD investigation was applied. The ultra-fine grained micro structure was examined with scanning electron microscope Tescan Lyra 3 equipped with Nordlys Nano EBSD detector operating at an accelerating voltage of $20 \mathrm{kV}$ with specimen tilted at $70^{\circ}$. Afterwards, the obtained data was analysed using HKL Channel 5 software developed by Oxford Instruments. Coarse grained micro structure grain sizes were measured with image processing programs after obtaining optical images. In order to obtain ultrafine grained grain size EBSD analyses were used.

Tensile test specimens were prepared with the form of dog bone shaped with $4 \times 1.5 \times 16$ (wide, thickness, length) by means of wire electro-discharge machine (EDM) and they were deformed at room temperature (RT) and at a strain rate of $1 \times 10^{-3} \mathrm{~s}^{-1}$. The sample dimensions are presented in Fig. 3. Specimens were tested from the parallel side to the extrusion direction. Two samples that belong to the best experimental set tested with tensile tests. A special gauge manufactured in order to adapted specimen to the tensile test machine. As highlighted in $^{29}$ this kind of inappropriate gauge length of tensile samples affects necking, ductility and so on. Thus, only maximum tensile strength was used from these tensile results.

In order to have a systematic approach to the selected ECAP process parameters experimental design Taguchi L27 was selected with three levels of factors (Table 1). Different process parameters are strongly effect quality characteristic which is homogenous micro structure in this study. The plan of the experiments was developed with the aim of understanding relation the influence of the pressing velocity, route and process temperature with the hardness of the specimen and minimize manufacturing cycles by finding the optimal manufacturing parameters ${ }^{30}$.

The statistical analysis was concerned with ANOVA to determine the percentage contribution of each parameter and their significance $\left(\mathrm{R}^{2}\right)$. Afterwards, the confirmations tests were applied. In Taguchi analysis, signal-to-noise $(\mathrm{S} / \mathrm{N})$ ratios were used to understand proper response of the levels. For the analysis of the $\mathrm{S} / \mathrm{N}$ ratio smaller-the better performance characteristic was used. The smaller better equation is given in Eq. 1.

$$
S / N=-10 \log \frac{1}{n}\left(\Sigma \frac{1}{y^{2}}\right)
$$

Quality characteristic is determined as microstructural homogeneity with lowest hardness value. Hardness measurements were applied transversal sections which are in perpendicular to the pressing direction. Hardness map obtained with optimal experimental set in order to understand microstructural homogeneity. For observation hardness values, measurement coordinates determined from cross section of specimen and from these determined points hardness values
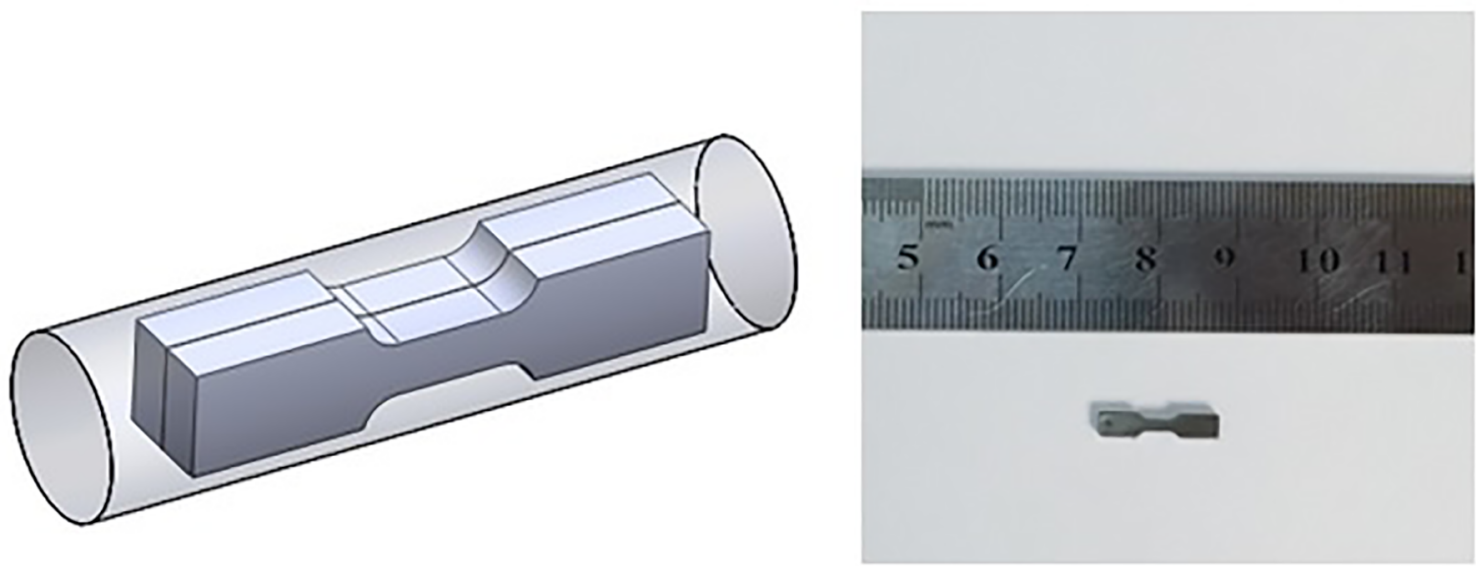

Figure 2. The experimental Set-up 


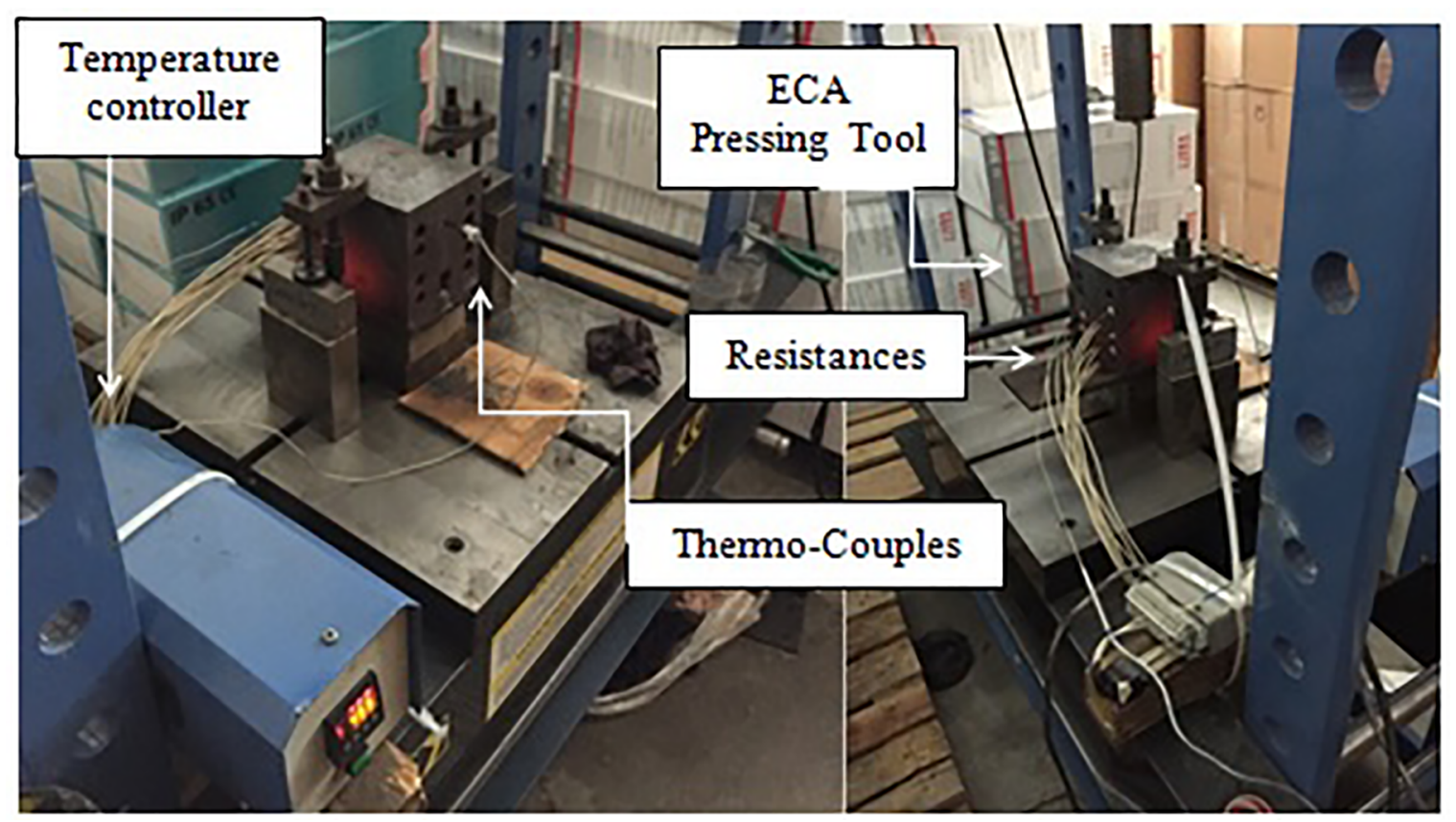

Figure 3. Tensile Specimen Geometriy

Table 1. Experimental design with Taguchi L27 and output values of sets

\begin{tabular}{|c|c|c|c|c|c|}
\hline Run & $\begin{array}{c}\text { Pressing Velocity (A) } \\
(\mathrm{mm} / \mathrm{sn})\end{array}$ & Process Temperature $(\mathrm{B})\left({ }^{\circ} \mathrm{C}\right)$ & Route (C) & $\begin{array}{c}\text { Hardness } \\
\text { HV }_{0.2}(\mathrm{MPa})\end{array}$ & $\begin{array}{c}\text { Standart Deviation } \\
(\mathrm{HV})\end{array}$ \\
\hline 1 & 0,1 & 450 & $\mathrm{~B}_{\mathrm{c}}$ & 2557 & 16,81 \\
\hline 2 & 0,1 & 450 & $\mathrm{~B}_{\mathrm{c}}$ & 2450 & 15,17 \\
\hline 3 & 0,1 & 450 & $\mathrm{~B}_{\mathrm{c}}$ & 2460 & 16,64 \\
\hline 4 & 0,1 & 300 & A & 2602 & 17,74 \\
\hline 5 & 0,1 & 300 & A & 2604 & 16,81 \\
\hline 6 & 0,1 & 300 & A & 2651 & 18,26 \\
\hline 7 & 0,1 & 150 & $\mathrm{C}$ & 2650 & 20,89 \\
\hline 8 & 0,1 & 150 & $\mathrm{C}$ & 2684 & 18,12 \\
\hline 9 & 0,1 & 150 & $\mathrm{C}$ & 2602 & 18,32 \\
\hline 10 & 0,5 & 300 & $\mathrm{~B}_{\mathrm{c}}$ & 2800 & 18,64 \\
\hline 11 & 0,5 & 300 & $\mathrm{~B}_{\mathrm{c}}$ & 2790 & 18,22 \\
\hline 12 & 0,5 & 300 & $\mathrm{~B}_{\mathrm{c}}$ & 2772 & 17,96 \\
\hline 13 & 0,5 & 150 & A & 2807 & 18,04 \\
\hline 14 & 0,5 & 150 & A & 2550 & 16,3 \\
\hline 15 & 0,5 & 150 & A & 2587 & 16,79 \\
\hline 16 & 0,5 & 450 & $\mathrm{C}$ & 2650 & 18,32 \\
\hline 17 & 0,5 & 450 & $\mathrm{C}$ & 2751 & 20,1 \\
\hline 18 & 0,5 & 450 & $\mathrm{C}$ & 2787 & 17,32 \\
\hline 19 & 5 & 150 & $\mathrm{~B}_{\mathrm{c}}$ & 3020 & 22,7 \\
\hline 20 & 5 & 150 & $\mathrm{~B}_{\mathrm{c}}$ & 3050 & 21,96 \\
\hline 21 & 5 & 150 & $\mathrm{~B}_{\mathrm{c}}$ & 2960 & 23,3 \\
\hline 22 & 5 & 450 & A & 2750 & 19,32 \\
\hline 23 & 5 & 450 & A & 2724 & 20,51 \\
\hline 24 & 5 & 450 & A & 2499 & 16,1 \\
\hline 25 & 5 & 300 & C & 3065 & 26,33 \\
\hline 26 & 5 & 300 & $\mathrm{C}$ & 3020 & 25,09 \\
\hline 27 & 5 & 300 & $\mathrm{C}$ & 3240 & 24,26 \\
\hline
\end{tabular}


measured (Fig. 4). Vickers hardness tester was used with $200 \mathrm{gf}$ and $10 \mathrm{~s}$ dwell time. 17 measurements with $0.9 \mathrm{~mm}$ step interval applied to each specimen in order to calculate standard deviation, hardness map is observed only for the optimum experimental set. In order to obtain hardness map 85 measurement applied with $0.4 \mathrm{~mm}$ measurement step interval. Sampling interval selected carefully in order to decrease indenter deformation effect on measurement result ${ }^{31}$. Moreover XRD analysis and tensile test applied to the optimum experimental set in order to understand ECAP effect. Phase measurements of initial state 1 pass and 8 pass specimen were conducted using an X-ray diffraction (XRD) Bruker AXS $\mathrm{D} 8$ diffractometer equipped with a $\mathrm{Co}-\mathrm{K} \alpha$ radiation source $(\lambda=1.5442 \AA)$. Samples for XRD were cut from the center of the ECAP billet perpendicular to the extrusion direction. Samples for XRD were mechanically polished with using 1200 grit SiC paper, followed by mechanical polishing with colloidal silica similar to the optical microscope surface preparation according to the relevant standard ${ }^{32,33}$.

Phase determination of all specimen were conducted using an X-ray diffraction (XRD) Bruker AXS D8 diffractometer equipped with a Co-K $\alpha$ radiation source $(\lambda=1.5442 \AA)$. Samples for XRD were cut from the center of the ECAP billet perpendicular to the extrusion direction. Samples for XRD were mechanically polished with using 1200 grit SiC paper, followed by mechanical polishing with colloidal silica.

\section{Results and Discussion}

The ECAP procedure was applied according to the selected experimental design and the mean hardness results are given in Table $1 . \mathrm{S} / \mathrm{N}$ rations for the hardness values of the specimen were calculated separately and given in Table 2 and Fig 5. The Taguchi results indicate the order of importance of the ECAP parameters for the hardness change as; pressing speed $>$ process temperature $>$ processing route (Table 2). The most significant process parameter found
Table 2. S/N Values obtained form hardness standard deviation

\begin{tabular}{lccc}
\hline Level & $\begin{array}{c}\text { Pressing } \\
\text { Velocity }\end{array}$ & $\begin{array}{c}\text { Process } \\
\text { Temperature }\end{array}$ & Route \\
\hline 1 & -24.92 & -25.52 & -25.02 \\
2 & -25.09 & -25.00 & -26.07 \\
3 & -26.87 & -26.36 & -25.80 \\
Delta & 1,95 & 1.36 & 1.05 \\
Rank & 1 & 2 & 3 \\
\hline
\end{tabular}

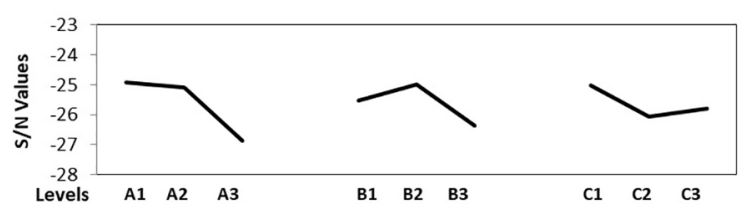

Figure 5. S/N graph obtained from hardness standard deviation

to be the pressing speed with a contribution of $45.25 \%$. Processing route found to be less effective parameter on microstructural homogeneity. Route $\mathrm{B}_{\mathrm{C}}$ is the optimal level beyond the routes which is parallel with the literatures ${ }^{10,11}$. This experimental design revealed the pressing speed and process temperature are much more effective on homogeneity than process route. As highlighted in the introduction part pressing velocity strongly affect deformation mechanism. Process parameters also known to be a crucial parameters strongly affect deformation mechanism and homogeneity. This experimental study revealed for these process parameters and their selected levels pressing speed is more affected than process temperature.

The analysis of variance (ANOVA) was performed in order to find the statistical significance and process parameters effect on the hardness homogeneity of ECA pressed samples with different manufacturing parameters. Table 3 indicates the results. Three important ECAP parameters investigated, as shown in Table 1; Pressing Velocity (mm/s) (A), Pressing Route (B), Process Temperature (C). P test and F test are
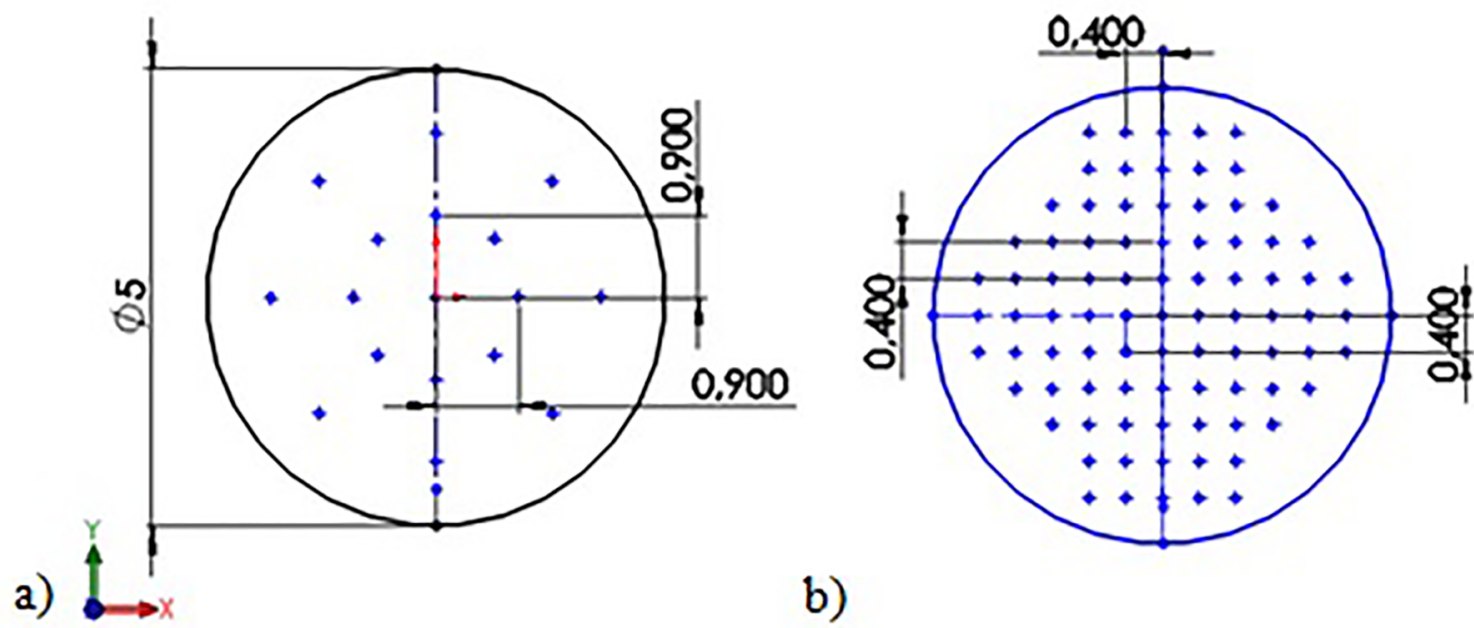

b)

Figure 4. a) Hardness measurement points for standard deviation calculations b) for homogeneity determination 
Table 3. ANOVA results for hardness homogeneity of specimens manufactured with experimental design parameter

\begin{tabular}{lccccccc}
\hline Source & DF & Seq SS & Adj SS & Adj MS & F-test & P & $\mathrm{F}_{0.05}$ \\
\hline A & 2 & 115.146 & 115.146 & 57.573 & 36.610 & 0.000 & Significant \\
B & 2 & 46.964 & 46.964 & 23.482 & 14.930 & 0.000 & Significant \\
C & 2 & 31.021 & 31.021 & 15.511 & 9.860 & 0.001 & Significant \\
Error & 20 & 31.448 & 31.448 & 1.572 & & & \\
Total & 26 & 224.578 & & & & & \\
$\mathrm{R}^{2}=86.00 \%$ & $\mathrm{R}^{2}(\operatorname{adj})=81.80 \%$ & & & & & \\
\hline
\end{tabular}

applied in order to understand the significance on the hardness change of these process parameters. P-values were tested which should be lower than 0.05 for $\% 95$ confidence level. Since P-values of all parameters were less than 0.05 , these values were significant according to the ANOVA analysis. Moreover for F-test all groups F results were higher than critic value (3.37) which supports $P$ test.

As can be seen in Figure 6 a, the plot grains shows equiaxed geometries with an average grain size of $\sim 67$ $\mu \mathrm{m}$ is observed with optical microscope. This specimen is pressed at $450{ }^{\circ} \mathrm{C}$ with route $\mathrm{B}_{\mathrm{c}}$. After first pass the grain size measured as $22 \mu \mathrm{m}$ without twins inside the grains according to the observations. The grain size decreasing is very effective for the first pass. After 2 pass the grain size measured as $9 \mu \mathrm{m}$ which proves the success of the ECAP grain size decreasing. Grain size decreasing is getting slower, due to the grain size range. As drawn in the Fig. $6 \mathrm{c}$ the grains geometries are still equiaxed due the deformation nature of the ECAP procedure.

After 8 passes electron back scattered diffraction method was used in order to measure UFG- 8 times pressed specimen grain size and investigation indicated the grain size as $\sim 520$ $\mathrm{nm}$ intercept measurement and $550 \mathrm{~nm}$ equivalent diameter. As can be seen in EBSD image there are different color which indicates different grains with different directions. During the pressing, at the intersection (Fig. 1 a) some planes are active and some grains are effected from strain and turns to different directions. Besides, some grains are not affected due to their slip planes and they stayed at the same color. This ECAP mechanism results with high grain boundary angles which is and another effect of ECAP procedure on specimen. There are also subgrains as shown in Fig. 7 EBSD image which can be noticed different colors in the some grain (marked with an arrow in the figure). These subgrains need dislocation in order to build up new stable grain boundary. These grains are unstable and these will be the first grains that can be change due to temperature or strains.

Selected specimens ultimate tensile strengths were tested repetitively at room temperature and the results are graphed in Fig. 7. The $\mathrm{x}$ row indicates the experimental run number; the specimen experimental parameters can be seen in Table 1. The y row indicates ultimate tensile strengths. As shown in Fig. 6 run 2 and the optimal experimental set according to the Taguchi and ANOVA results showed the

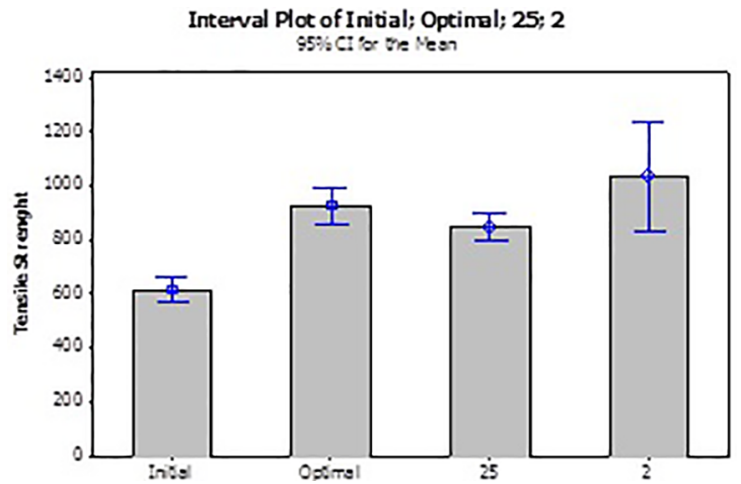

Figure 6. The microstructure of pure $\mathrm{Ti}$ (a) in as-received condition, (b) after 1 passes of ECAP processing, (b) 2 pass c) 3 pass (d) 4 pass e) 5 pass (f) 6 pass and (g) 7 pass (h) 8 pass of ECAP pressing at $450{ }^{\circ} \mathrm{C}$

ultimate tensile strength. As can been seen maximum tensile strength was increased with the ECAP pass number. This result is accordance with Hall-Patch equation. Besides this both 8 pass specimens; optimal, run 25 and Run 2 have different maximum tensile strengths. As given in Figure 7 experimental design run 2 had the highest tensile strength. Run 2 had the lowest press speed with $0.1 \mathrm{~mm} / \mathrm{sn}, 450{ }^{\circ} \mathrm{C}$ working temperature and $\mathrm{B}_{\mathrm{c}}$ processing route. Run 25 had the highest press speed with $5 \mathrm{~mm} / \mathrm{sn}, 300^{\circ} \mathrm{C}$ working temperature and A processing route. These process parameters were also affected homogeneity, deformation mechanism and tensile strength. Pure titanium is a material with high stacking fault energy which effect deformation mechanism dependent to the process temperature ${ }^{28,29}$. For example deformation at higher temperatures high stacking fault energy enables deformation climbs. Also at lower temperatures such as 300 ${ }^{\circ} \mathrm{C}$, twinning seems to be more effective as deformation mechanism ${ }^{18,19,}$. These mechanism affect final tensile strength and microstructural homogeneity. As seen inFigure 7 Run 2 had the highest tensile strength with a lower hardness value and with lower standard deviation than Run 25. Decreased hardness can point softening due to continuous dynamic recrystallization and lower hardening due to increased process temperature. Besides increased maximum tensile strength hardness deviation is worse for Run 25. High processing speed is one of the important process parameters that effect microstructure. Lower press speeds enable dislocation mobility that effects microstructural homogeneity and improves 


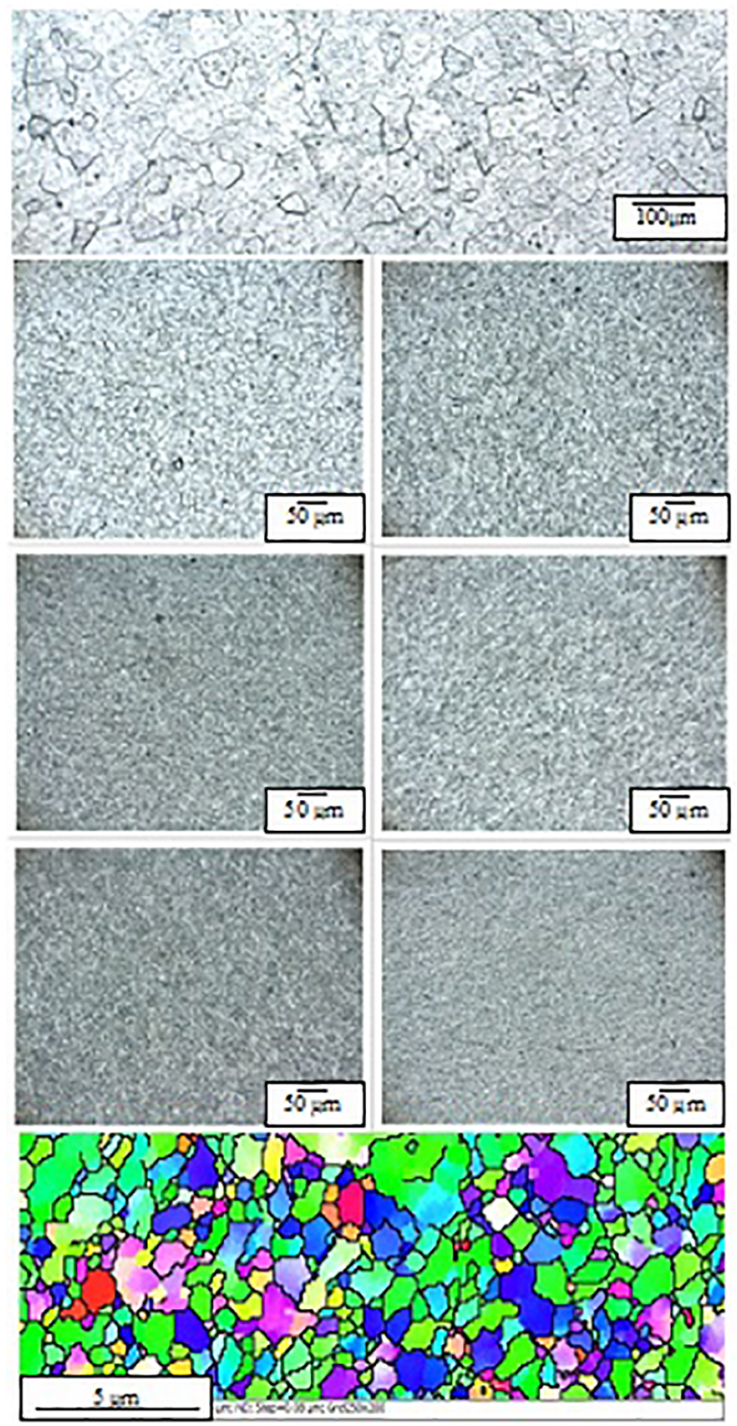

Figure 7. Ultimate Tensile Strength of Specimens

grain size decreasing mechanism also related with tensile strength according to the Hall-Patch ${ }^{30,34,35}$. According to the Taguchi analysis optimal parameter set give the best result for homogeneity. Despite of maximum tensile strength relative to the Run 25, hardness distribution was the lowest which points good microstructural homogeneity

XRD graphs obtained for 8,1 passes and initial state of material and they are provided in Fig. 8. As can be seen in Figure 8 ECAP deformation mechanism did not caused stress induced phase transformation, all of the peeks belong to alpha phases. Peek shifts (shown in Fig. 8 with red lines for $101 \alpha$ and $110 \alpha \mathrm{Ti}$ ) are observed which indicated high strains in the structure due to ECAP deformation. The shifts increased with the increase of ECAP passes. Also the height and width of the peaks are changes due to increased strain. Besides as drawn in Fig. 8 the height of the peak (In Fig.8h) that belongs to $101 \mathrm{c} \mathrm{Ti}$ is increased and the peak width (in

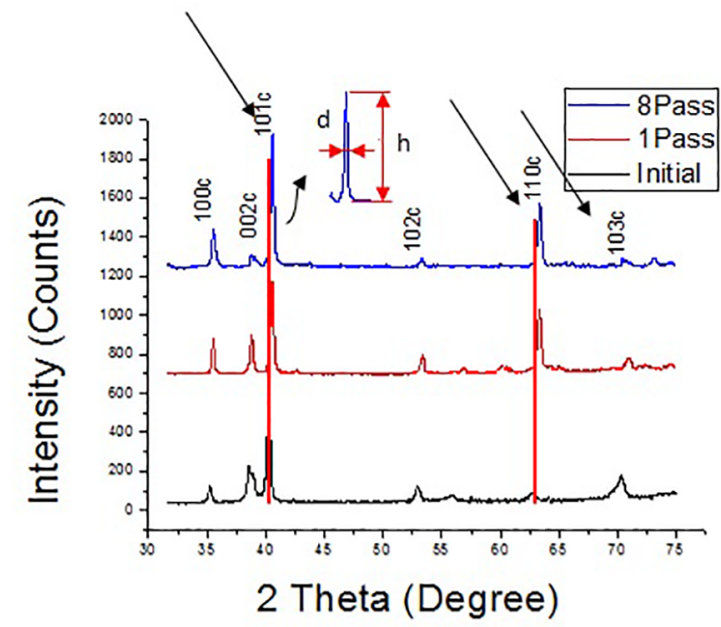

Figure 8. XRD profiles of samples processed by ECAP with 1 pass and 8 passes, including initial state

Fig 8 d) of the peak decreased. According to the XRD counts the height was 650 for 8 times pressed sample and it was 550 for initial state. The peak width decreased to $0.0587^{\circ}$ from $0.0871^{\circ}$. Some peaks heights decreased as shown in Fig. 8 $103 \mathrm{c}$ which is the nature of SPD. During SPD procedure some of the grain can be stress relief due to thermal stress induced recovery and deformation plane direction.

After determination of optimal experimental set a more detail hardness map observed with 85 different hardness measurement points and the results were given in Fig. 9. The colour scale is given on the right of the graph in order to indicate the significance levels of the hardness results. The hardness map is given is Fig. 9. The hardness changed between $250-341 \mathrm{Hv}_{0.2}$, a clear majority of hardness values were close to the mean hardness. The mean hardness value is calculated as $298.4 \mathrm{Hv}_{0.2}$ with a deviation of 12.07 . This confirms experimental design results. The hardness is mostly homogeneous and partially higher in outer sections as shown in Fig. 9. Friction between ECAP channel walls and specimen during the ECAP procedure is higher for the outer

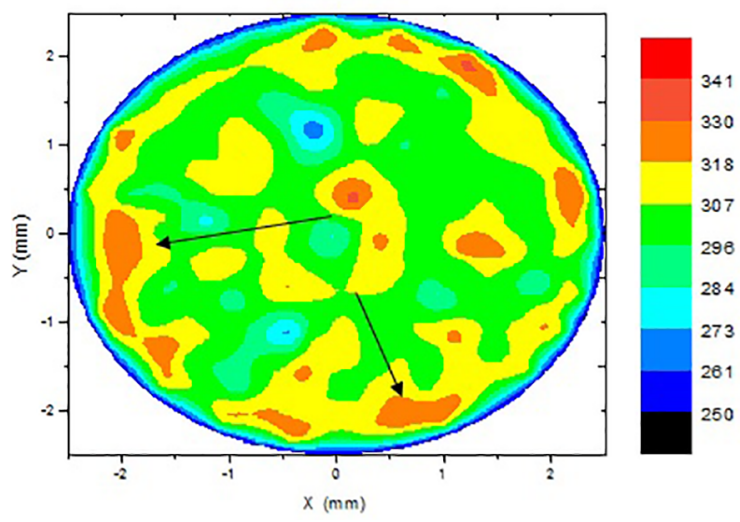

Figure 9. Hardness Map of 8 pass specimen with 0.1 pressing velocity, $300 \mathrm{C}$ pressing temperature and route $\mathrm{Bc}$ 
areas of the specimens. This hardness increase thought to be as a consequence of this high friction rate during ECAP.

\section{Conclusions}

Evolution of a proper microstructure for the needed properties is strongly related to microstructure formation based on stress-strain history. Thus, processing optimization enables to obtain needed material structure. Besides, technique also helps to understand parameters effect on microstructure.

- According to the $\mathrm{S} / \mathrm{N}$ graph A1, B2 and C1 were found as optimal experimental design set which corresponds $0.1 \mathrm{~mm} / \mathrm{s}$ pressing velocity; $300{ }^{\circ} \mathrm{C}$ temperature and route $\mathrm{B}_{\mathrm{c}}$. Pressing at room temperature were tried but failed by segmentations for pressing speed $5-0.1 \mathrm{~mm} / \mathrm{s}$.

- Despite the significant effect of processing route to invoke deformation planes, pressing velocity founded to the most effective parameter for $150{ }^{\circ} \mathrm{C}, 300{ }^{\circ} \mathrm{C}$, $450{ }^{\circ} \mathrm{C}$ temperature and $\mathrm{A}, \mathrm{B}, \mathrm{C}$ routes with $48.5 \%$.

- XRD analysis indicated the material phases correspond to the $\alpha$ phase, which indicates that no phase transformation occurred during ECAP procedure of 8 pass specimen.

- The tensile test results indicate optimal experimental run showed the highest tensile strength.

- $\quad$ EBSD analysis were used in order to measure grain size of ultrafine grained specimen and grain size found as $\sim 520 \mathrm{~nm}$ intercept measurement and $550 \mathrm{~nm}$ equivalent diameter.

\section{Acknowledgements}

The authors would like to thank Dr. Petr Král for his valuable EBSD contribution from Academy of Sciences of the Czech Republic Institute of Physics of Materials.

The authors also would like to thank TEM Technical Electrical Materials Industry and Trade Inc. for their technical support.

\section{References}

1. Ghiabakloo H, Lee K, Kazeminezhad M, Kang BS. Surrogatebased Pareto optimization of annealing parameters for severely deformed steel. Materials \& Design. 2016;92:1062-1069.

2. Siddesha HS, Shantharaja M. Characterization of Mechanical Properties of Aluminum Processed by Repetitive Corrugation and Straightening Process using Taguchi Analysis. JOM. 2013;65(2):294-298.

3. Iqbal UM, Kumar VSS, Gopalakannan S. Application of Response Surface Methodology in optimizing the process parameters of Twist Extrusion process for AA6061-T6 aluminum alloy. Measurement. 2016;94:126-138.
4. Kim I, Kim J, Shin DH, Lee CS, Hwang SK. Effects of equal channel angular pressing temperature on deformation structures of pure Ti. Materials Science and Engineering: A. 2003;342(12):302-310.

5. Günay Bulutsuz A, Berrak Ö, Yeprem HA, Arisan ED, Yurci ME. Biological responses of ultrafine grained pure titanium and their sand blasted surfaces. Materials Science and Engineering: C. 2018;91:382-388.

6. Segal VM. Materials processing by simple shear. Materials Science and Engineering: A. 1995;197(2):157-164.

7. Furukawa M, Iwahashi Y, Horita Z, Nemoto M, Langdon TG. The shearing characteristics associated with equal-channel angular pressing. Materials Science and Engineering: $A$. $1998 ; 257(2): 328-332$.

8. Yamashita A, Yamaguchi D, Horita Z, Langdon TG. Influence of pressing temperature on microstructural development in equalchannel angular pressing. Materials Science and Engineering: A. 2000;287(1):100-106.

9. Segal VM. Equal channel angular extrusion: from macromechanics to structure formation. Materials Science and Engineering: $A$. 1999;271(1-2):322-333. DOI: 10.1016/S0921-5093(99)00248-8

10. Shin DH, Kim I, Kim J, Kim YS, Semiatin SL. Microstructure development during equal-channel angular pressing of titanium. Acta Materialia. 2003;51(4):983-996.

11. Stolyarov VV, Zhu YT, Alexandrov IV, Lowe TC, Valiev RZ. Influence of ECAP routes on the microstructure and properties of pure Ti. Materials Science and Engineering: A. 2001:299(12):59-67.

12. Ko YG, Lee CS, Shin DH, Semiatin SL. Low-temperature superplasticity of ultra-fine-grained Ti-6Al-4V processed by equal-channel angular pressing. Metallurgical and Materials Transactions A. 2006;37:381-391.

13. Shin DH, Kim I, Kim J. Deformation Mechanisms of Pure Ti during equal channel angular pressing. Metals and Materials International. 2002;8:513-518

14. Merklein M, Allwood JM, Behrens BA, Brosius A, Hagenah H, Kuzman K, et al. Bulk forming of sheet metal. CIRP Annals. 2012:61(2):725-745.

15. Numakura H, Koiwa M. Dislocations in metals and alloys with the hexagonal close-packed structure. Metallurgical Science and Technology. 1998;16(1-2):4-19.

16. Kim I, Jeong WS, Kim J, Park KT, Shin DH. Deformation structures of pure Ti produced by equal channel angular pressing. Scripta Materialia. 2001;45(5):575-580.

17. Yoo MH. Slip, twinning, and fracture in hexagonal close-packed metals. Metallurgical Transactions A. 1981;12(3):409-418.

18. Yoo MH, Morris JR, Ho KM, Agnew SR. Nonbasal deformation modes of HCP metals and alloys: Role of dislocation source and mobility. Metallurgical and Materials Transactions A. 2002;33(3):813-822.

19. Kim I, Kim J, Shin DH, Liao XZ, Zhu YT. Deformation twins in pure titanium processed by equal channel angular pressing. Scripta Materialia. 2003;48(6):813-817. 
20. Stolyarov VV, Zhu YT, Lowe TC, Valiev RZ. Microstructure and properties of pure Ti processed by ECAP and cold extrusion. Materials Science and Engineering: A. 2001;303(1-2):82-89.

21. Liu X, Zhang Q, Zhao X, Yang X, Luo L. Ambient-temperature nanoindentation creep in ultrafine-grained titanium processed by ECAP. Materials Science and Engineering: A. 2016;676:73-79.

22. Yang XR, Zhao XC, Liu XY. Microstructure and Mechanical Properties of CP-Ti Processed by 2 ECAP Passes Using a $90^{\circ}$ Die at Room Temperature. Materials Science Forum. 2011;682:103-108.

23. Kim HS. Evaluation of Strain Rate During Equal-channel Angular Pressing. Journal of Materials Research. 2002;17(1):172-179.

24. Semiatin SL, Berbon PB, Langdon TG. Deformation heating and its effect on grain size evolution during equal channel angular extrusion. Scripta Materialia. 2001;44(1):135-140.

25. Moradi M, Basu S, Shankar MR. In situ measurement of deformation mechanics and its spatio-temporal scaling behavior in equal channel angular pressing. Journal of Materials Research. 2015;30(6):798-810.

26. Yamaguchi D, Horita Z, Nemoto M, Langdon TG. Significance of adiabatic heating in equal- channel angular pressing. Scripta Materialia. 1999;41(8):791-796.

27. Pei QX, Hu BH, Lu C, Wang YY. A finite element study of the temperature rise during equal channel angular pressing. Scripta Materialia. 2003;49(4):303-308.

28. Quang P, Nghiep DM, Kim YJ. Simulation of Effective Stress and Temperature Field of the Die and Workpiece during ECAP of pure Titanium at different Ram Speeds by Finite Volume Method. Key Engineering Materials. 2015;656-657:532-537.
29. Zhao YH, Guo YZ, Wei Q, Dangelewicz AM, Xu C, Zhu $\mathrm{YT}$, et al. Influence of specimen dimensions on the tensile behavior of ultrafine-grained Cu. Scripta Materialia. 2008;59(6):627-630.

30. Weckenmann A, Brenner PF. Process Optimization Using a Shop Floor Integrated Advisory And Assistance System for Design of Experiments (DoE) - An Application in Electronics Manufacturing. VDI Berichte. 2004;1860:197-204.

31. Pawlus P, Reizer R, Wieczorowski M, Zelasko W. The Effect of sampling interval on the predictions of an asperity contact model of two-process surfaces. Bulletin of The Polish Academy of Sciences - Technical Sciences. 2017;65(3):391398.

32. Beuth Verlag. DIN EN ISO 4499-1:2010-10. HartmetalleMetallographische Bestimmung der Mikrostruktur-Teil 1: Gefügebilder und Beschreibung (ISO 4499-1:2008). Berlin: Beuth Verlag; 2010.

33. Beuth Verlag. DIN EN ISO 4499-3:2016. Hartmetalle Metallographische Bestimmung der Mikrostruktur - Teil 3: Messung von mikrostrukturellen Merkmalen in Hartmetallen auf Basis von $\mathrm{Ti}(\mathrm{C}, \mathrm{N})$ und WC/kubischem Carbid (ISO 4499-3:2016). Berlin: Beuth Verlag; 2016.

34. Weertman J. Theory of the influence of stacking-fault width of split dislocations on high-temperature creep rate. Transactions of the Metallurgical Society of AIME. 1965;233:2069-2075.

35. Zheng Z, Balint DS, Dunne FPE. Rate sensitivity in discrete dislocation plasticity in hexagonal close-packed crystals. Acta Materialia. 2016;107:17-26. 